\title{
Sex and age differences in COVID-19 mortality in Europe
}

\author{
Linda Juel Ahrenfeldt · Martina Otavova · Kaare Christensen · Rune Lindahl-Jacobsen
}

Received: 20 July 2020 / Accepted: 30 November 2020 / Published online: 22 December 2020

(C) Springer-Verlag GmbH Austria, part of Springer Nature 2020

\begin{abstract}
Summary
Aim To examine the magnitude of sex differences in survival from the coronavirus disease 2019 (COVID19) in Europe across age groups and regions. We hypothesized that men have a higher mortality than women at any given age but that sex differences will decrease with age as only the healthiest men survive to older ages.

Methods We used population data from the Institut National D’Études Démographiques on cumulative deaths due to COVID-19 from February to June 2020 in 10 European regions: Denmark, Norway, Sweden, The Netherlands, England and Wales, France, Germany, Italy, Spain and Portugal. For each region, we calculated cumulative mortality rates stratified by age and sex and corresponding relative risks for men vs. women.
\end{abstract}

\section{Supplementary Information The online version of this article (https://doi.org/10.1007/s00508-020-01793-9) contains supplementary material, which is available to authorized users.}

L. J. Ahrenfeldt $(\bowtie) \cdot$ M. Otavova $\cdot$ K. Christensen .

R. Lindahl-Jacobsen

Unit of Epidemiology, Biostatistics and Biodemography, Department of Public Health, University of Southern Denmark, J.B. Winsløws Vej 9B, 5000 Odense C, Denmark lahrenfeldt@health.sdu.dk

\section{Otavova $\cdot$ R. Lindahl-Jacobsen}

Interdisciplinary Center on Population Dynamics, University of Southern Denmark, 5000 Odense, Denmark

\section{K. Christensen}

Danish Aging Research Center, Department of Public Health, University of Southern Denmark, 5000 Odense, Denmark

Department of Clinical Biochemistry and Pharmacology, Odense University Hospital, 5000 Odense, Denmark

Department of Clinical Genetics, Odense University Hospital, 5000 Odense, Denmark
Results The relative risk of dying from COVID-19 was higher for men than for women in almost all age groups in all regions. The overall relative risk ranged from 1.11 (95\% confidence interval, CI 1.01-1.23) in Portugal to 1.54 (95\% CI 1.49-1.58) in France. In most regions, sex differences increased until the ages of 60-69 years, but decreased thereafter with the smallest sex difference at age $80+$ years.

Conclusion Despite variability in data collection and time coverage among regions, the study showed an overall similar pattern of sex differences in COVID-19 mortality in Europe.

Keywords SARS-CoV-2 - Cumulative mortality rates · Sex difference $\cdot$ Relative risks $\cdot$ European regions

\section{Introduction}

Despite the fact that women suffer greater morbidity than men, particularly late in life [1], women outlive men in almost all countries of the world [2]. This is the case even under the harshest conditions where mortality is very high, e.g. during severe famines and epidemics [3]. Since December 2019, the emergence of the coronavirus disease 2019 (COVID-19) has been reported in Wuhan, China, with infection outbreaks across China and around the world [4, 5]. Data from early reported cases in China suggested that the mortality rate from COVID-19 is higher for infected men than for infected women [6-8] with fatality rates of $2.8 \%$ in men vs. $1.7 \%$ in women [8]. A recent study from mainland China found that the case fatality rate (CFR, the risk of dying among persons diagnosed with COVID-19) was lower in female patients $(4.0 \%)$ than in male patients $(7.2 \%)$; however, sex differences varied between regions and were age-dependent with significant differences among patients aged 30 years and above [9]. In agreement 
with this finding, the Global Health 50/50 research initiative, which presents an overview of sex-disaggregated data from countries worldwide, demonstrated that despite similar numbers of COVID-19 cases in men and women there is an increased CFR in men [10]. A review collecting epidemiological data on confirmed COVID-19 cases in Europe and China until 1 April 2020 found that the male to female COVID19 CFRs reported from France, Italy, Spain, Germany, Switzerland and China were relatively homogeneous and ranged between 1.7 and 1.8 [11]. In addition, pooled data from Italy, Spain, Germany and Switzerland comprising 227,219 confirmed cases and 14,364 deaths suggested that although the male to female CFR was consistently elevated through all age groups, the sex difference was most pronounced at middle age, particularly at ages 50-59 years [11]. Correspondingly, data on COVID-19 cases and deaths obtained from outbreaks in China, Italy and New York City demonstrated a higher mortality for men than for women at all ages, with the scale of difference between sexes being consistent with that found for more common causes of mortality, such as heart disease [12].

Here we examine the magnitude of sex differences in survival from COVID-19 across age groups and regions in Europe. This will enable us to investigate the consistency of sex differences across regions and thus to map the epidemiology of the disease; however, due to the highly variable rate of COVID-19 by age, also the age-specific mortality from COVID-19 is considered. We hypothesized that men have higher mortality than women at any given age, but that sex differences in mortality from COVID-19 will decrease with age as only the healthiest men survive to older ages [1].

\section{Material and methods}

\section{Study population}

This study was based on 10 European regions (Denmark, Norway, Sweden, The Netherlands, England and Wales, France, Germany, Italy, Spain and Portugal) that reported daily cumulative deaths due to COVID-19 by sex and age available from the Institut National D’Études Démographiques (INED) website [13]. The data collection methods and the time period covered differed for each region with the earliest date of 14 February 2020 and the latest date of 29 June 2020 (see Supplementary Table 1). Sex-specific and age-specific population sizes (numbers) for the 10 European regions can be found in Supplementary Table 2.

\section{Statistical analysis}

Sex-specific cumulative mortality rates (CMR) from COVID-19 per 100,000 men and women were calcu- lated for each day for the covered time periods in each region. In addition, CMR and relative risks (RR) with $95 \%$ confidence intervals $(\mathrm{CI})$ were calculated in each region in four age groups ( $<60$ years, 60-69 years, 70-79 years and $80+$ years) using data from the last day covered by the study. The Wald test was used to investigate differences between the RRs of adjacent age groups.

\section{Results}

In all European regions, the CMRs increased with advancing age (Table 1). The highest CMRs were found in England and Wales with 91.0 (95\% CI 89.9-92.1) per 100,000 men and 72.4 (95\% CI 71.4-73.3) per 100,000 women. High CMRs were also found in two Southern European regions, Italy (66.2, 95\% CI 65.3-67.2 per 100,000 men and $45.4,95 \%$ CI 44.7-46.2 per 100,000 women) and Spain (50.3, 95\% CI $49.4-51.2$ per 100,000 men and 37.2 , 95\% CI 36.4-38.0 per 100,000 women). The regions with the lowest mortality from COVID-19 were Norway (5.0, 95\% CI 4.2-5.9 per 100,000 men and 4.3, 95\% CI 3.6-5.2 per 100,000 women), Denmark (11.8, 95\% CI 10.6-13.2 per 100,000 men and 8.9 , 95\% CI 7.9-10.0 per 100,000 women), and Germany (12.1, 95\% CI 11.8-12.5 per 100,000 men and $9.5,95 \%$ CI 9.2-9.8 per 100,000 women) (Table 1). The patterns for the CMRs between February and June 2020 revealed an overall similar trend for men and women; however, higher CMRs were found for men than for women, particularly in Western and Southern Europe (Supplementary Fig. 1).

When investigating the RRs for men vs. women, we found higher mortality among men in all age groups except from ages $<60$ years for Denmark and Norway and ages $80+$ years for Norway (Table 1). The overall RRs ranged from 1.11 (95\% CI 1.01-1.23) in Portugal to 1.54 (95\% CI $1.49,1.58)$ in France; however, the overall RR in Norway was non-significant $(\mathrm{RR}=1.15$, 95\% CI 0.89-1.47). In most regions, sex differences increased from ages $<60$ years to $60-69$ years but decreased thereafter (Table 1). Although not all differences in RRs between adjacent age groups were significant, differences in RRs between the oldest age groups were significant in all regions (Table 1). The largest sex differences were found at ages 60-69 years in Norway, England and Wales, Germany and Italy, up to age 69 years in Sweden, up to age 79 years in the Netherlands, France and Portugal, from 60-79 years in Spain and at ages 70-79 years in Denmark. The smallest sex difference was found at ages $80+$ years in all regions (Table 1). Supplementary Fig. 2 illustrates the RRs for men vs. women in the four age groups across Europe. We found the largest sex difference in Norway ( $R R=4.27,95 \%$ CI 0.92-19.76), Sweden $(\mathrm{RR}=3.03,95 \% \mathrm{CI} 2.17-4.24)$, and Italy $(\mathrm{RR}=2.91$, 95\% CI 2.59-3.26) for people below age 60 years, in Norway $(\mathrm{RR}=5.97,95 \% \mathrm{CI} 1.76-20.28)$, Italy $(\mathrm{RR}=3.49$, 
Table 1 Cumulative mortality rates (CMRs) of COVID-19 per 100,000 men and women and relative risks (RRs) for men vs. women with $95 \%$ confidence intervals (Cls) over age groups by 10 European regions

\begin{tabular}{|c|c|c|c|c|c|c|}
\hline & CMR & $95 \% \mathrm{Cl}$ & CMR & $95 \% \mathrm{Cl}$ & RR & $95 \% \mathrm{Cl}$ \\
\hline \multicolumn{7}{|l|}{ Denmark } \\
\hline Overall & 11.84 & (10.64-13.18) & 8.92 & $(7.88-10.01)$ & 1.33 & $(1.13-1.56)$ \\
\hline$<60$ years & 0.55 & $(0.96-0.99)$ & 0.23 & $(0.08-0.58)$ & 2.33 & $(0.82-6.61)$ \\
\hline $60-69$ years & 11.34 & $(8.10-1.58)$ & 6.52 & $(4.19-10.10)$ & 1.74 & $(1.03-2.95)$ \\
\hline $70-79$ years & 45.88 & (38.29-54.94) & 16.54 & (12.36-22.05) & 2.77 & $(1.99-3.86)^{\mathrm{a}}$ \\
\hline $80+$ years & 157.62 & (135.28-183.55) & 112.92 & (97.50-13.07) & 1.40 & $(1.13-1.72)^{\mathrm{a}}$ \\
\hline \multicolumn{7}{|l|}{ Norway } \\
\hline Overall & 4.95 & $(4.17-5.88)$ & 4.32 & $(3.58-5.21)$ & 1.15 & $(0.89-1.47)$ \\
\hline$<60$ years & 0.43 & $(0.21-0.84)$ & 0.10 & $(0.02-0.40)$ & 4.27 & $(0.92-19.76)$ \\
\hline $60-69$ years & 6.17 & $(3.77-9.96)$ & 1.03 & $(0.27-3.29)$ & 5.97 & $(1.76-20.28)$ \\
\hline $70-79$ years & 18.04 & (12.94-25.03) & 8.44 & $(5.23-13.45)$ & 2.14 & $(1.23-3.71)^{\mathrm{a}}$ \\
\hline $80+$ years & 76.30 & (59.81-97.16) & 64.87 & (52.53-80.03) & 1.18 & $(0.86-1.61)^{\mathrm{a}}$ \\
\hline \multicolumn{7}{|l|}{ Sweden } \\
\hline Overall & 52.27 & (50.33-54.29) & 46.11 & $(44.27-48.01)$ & 1.13 & $(1.07-1.20)$ \\
\hline$<60$ years & 3.65 & $(3.09-4.31)$ & 1.20 & $(0.87-1.62)$ & 3.03 & $(2.17-4.24)$ \\
\hline $60-69$ years & 40.22 & (35.18-45.97) & 16.53 & $(13.40-20.37)$ & 2.43 & $(1.91-3.10)$ \\
\hline $70-79$ years & 142.07 & (131.69-153.25) & 76.42 & (69.11-84.49) & 1.86 & $(1.64-2.10)^{\mathrm{a}}$ \\
\hline $80+$ years & 773.56 & (737.25-811.64) & 573.95 & $(548.22-600.86)$ & 1.35 & $(1.26-1.44)^{\mathrm{a}}$ \\
\hline \multicolumn{7}{|c|}{ The Netherlands } \\
\hline Overall & 39.13 & (37.83-40.48) & 31.59 & $(30.43-32.80)$ & 1.24 & $(1.18-1.30)$ \\
\hline$<60$ years & 1.98 & $(1.66-2.36)$ & 0.97 & $(0.75-1.26)$ & 2.04 & $(1.50-2.76)$ \\
\hline 60-69 years & 31.98 & (28.68-35.66) & 15.78 & (13.51-18.42) & 2.03 & $(1.68-2.44)$ \\
\hline 70-79 years & 142.95 & (134.45-151.95) & 74.26 & (68.44-80.58) & 1.92 & $(1.74-2.13)$ \\
\hline $80+$ years & 601.69 & (574.82-629.79) & 393.81 & (376.57-411.82) & 1.53 & $(1.43-1.62)^{\mathrm{a}}$ \\
\hline \multicolumn{7}{|c|}{ England and Wales } \\
\hline Overall & 90.99 & (89.90-92.09) & 72.36 & (71.40-73.32) & 1.26 & $(1.23-1.28)$ \\
\hline$<60$ years & 9.00 & $(8.62-9.40)$ & 5.06 & $(4.77-5.36)$ & 1.78 & $(1.66-1.91)$ \\
\hline $60-69$ years & 100.84 & (97.32-104.48) & 50.04 & $(47.64-52.57)$ & 2.01 & $(1.90-2.14)^{\mathrm{a}}$ \\
\hline $70-79$ years & 296.63 & (289.67-303.75) & 156.15 & (151.39-161.07) & 1.90 & $(1.82-1.97)^{\mathrm{a}}$ \\
\hline $80+$ years & 1234.8 & (1214.91-1254.77) & 848.04 & (834.55-861.75) & 1.46 & $(1.42-1.48)^{\mathrm{a}}$ \\
\hline \multicolumn{7}{|l|}{ France } \\
\hline Overall & 34.81 & $(34.18-35.46)$ & 22.65 & (22.16-23.17) & 1.54 & (1.49-1.58) \\
\hline$<60$ years & 3.45 & $(3.22-3.69)$ & 1.69 & $(1.54-1.86)$ & 2.04 & $(1.81-2.29)$ \\
\hline 60-69 years & 42.82 & (40.78-44.97) & 15.88 & (14.71-18.65) & 2.70 & $(2.46-2.95)^{\mathrm{a}}$ \\
\hline $70-79$ years & 114.51 & $(110.45-118.71)$ & 43.42 & (41.14-45.82) & 2.64 & $(2.47-2.81)$ \\
\hline $80+$ years & 390.98 & (381.06-401.15) & 203.60 & (19.82-20.91) & 1.92 & $(1.85-1.99)^{\mathrm{a}}$ \\
\hline \multicolumn{7}{|l|}{ Germany } \\
\hline Overall & 12.11 & $(11.77-12.45)$ & 9.50 & $(9.21-9.80)$ & 1.27 & (1.22-1.33) \\
\hline$<60$ years & 1.01 & $(0.91-1.14)$ & 0.40 & $(0.33-0.48)$ & 2.55 & $(2.06-3.16)$ \\
\hline $60-69$ years & 12.63 & (11.67-13.67) & 4.21 & (3.69-4.81) & 2.99 & $(2.57-3.49)^{\mathrm{a}}$ \\
\hline 70-79 years & 38.79 & (36.77-40.92) & 15.76 & (14.59-17.02) & 2.46 & $(2.42-2.70)^{\mathrm{a}}$ \\
\hline $80+$ years & 131.46 & (126.53-136.57) & 89.09 & (85.94-92.35) & 1.48 & $(1.40-1.55)^{\mathrm{a}}$ \\
\hline \multicolumn{7}{|l|}{ Italy } \\
\hline Overall & 66.24 & $(65.31-67.17)$ & 45.42 & (44.68-46.18) & 1.46 & $(1.43-1.49)$ \\
\hline$<60$ years & 5.37 & $(5.06-5.69)$ & 1.85 & $(1.67-2.04)$ & 2.91 & $(2.59-3.26)$ \\
\hline $60-69$ years & 73.80 & (70.99-76.71) & 21.12 & (19.70-22.64) & 3.49 & $(3.23-3.78)^{\mathrm{a}}$ \\
\hline $70-79$ years & 226.55 & (220.96-232.28) & 83.51 & (80.41-86.73) & 2.71 & $(2.59-2.83)^{\mathrm{a}}$ \\
\hline $80+$ years & 594.16 & (582.36-606.20) & 373.17 & (365.98-380.49) & 1.59 & $(1.55-1.63)^{\mathrm{a}}$ \\
\hline \multicolumn{7}{|l|}{ Spain } \\
\hline Overall & 50.27 & $(49.37-51.20)$ & 37.18 & $(36.41-37.96)$ & 1.35 & (1.32-1.39) \\
\hline$<60$ years & 3.76 & $(3.48-4.06)$ & 1.74 & $(1.55-1.95)$ & 2.17 & (1.89-2.48) \\
\hline 60-69 years & 50.41 & $(47.70-53.26)$ & 19.72 & (18.11-21.47) & 2.56 & $(2.31-2.83)^{\mathrm{a}}$ \\
\hline $70-79$ years & 187.42 & (181.13-193.93) & 73.52 & (69.95-77.28) & 2.55 & $(2.40-2.70)$ \\
\hline $80+$ years & 597.80 & $(583.26-612.70)$ & 362.22 & (353.52-371.13) & 1.65 & $(1.60-1.70)^{\mathrm{a}}$ \\
\hline
\end{tabular}


Table 1 (Continued)

\begin{tabular}{|c|c|c|c|c|c|c|}
\hline & CMR & $95 \% \mathrm{Cl}$ & CMR & $95 \% \mathrm{Cl}$ & RR & $95 \% \mathrm{Cl}$ \\
\hline \multicolumn{7}{|l|}{ Portugal } \\
\hline Overall & 16.12 & $(15.02-17.30)$ & 14.49 & $(13.50-15.55)$ & 1.11 & $(1.01-1.23)$ \\
\hline$<60$ years & 1.30 & $(9.69-1.75)$ & 0.66 & $(0.44-0.99)$ & 1.96 & $(1.21-3.19)$ \\
\hline $60-69$ years & 16.29 & (13.28-19.94) & 6.65 & $(4.93-8.95)$ & 2.45 & $(1.72-3.48)$ \\
\hline $70-79$ years & 43.76 & (37.74-50.72) & 21.87 & (18.21-26.25) & 2.00 & $(1.59-2.52)$ \\
\hline $80+$ years & 192.50 & (175.44-211.20) & 140.14 & (129.22-151.98) & 1.37 & $(1.22-1.55)^{\mathrm{a}}$ \\
\hline
\end{tabular}

95\% CI 3.23-3.78) and Germany $(\mathrm{RR}=2.99$, 95\% CI 2.57-3.49) for people aged 60-69 years, in Denmark $(\mathrm{RR}=2.77,95 \%$ CI $1.99-3.86)$, Italy $(\mathrm{RR}=2.71,95 \% \mathrm{CI}$ 2.59-2.83) and France $(\mathrm{RR}=2.64,95 \%$ CI $2.47-2.81)$ for people aged 70-79 years and in France $(\mathrm{RR}=1.92$, 95\% CI 1.85-1.99), Spain ( $R R=1.65$, 95\% CI 1.60-1.70) and Italy $(\mathrm{RR}=1.59,95 \% \mathrm{CI} 1.55-1.63)$ for people aged 80+ years (Supplementary Fig. 2 and Table 1). Overall, the largest sex differences in COVID-19 mortality were found in France, Italy and Spain.

\section{Discussion}

By using population estimates from the INED website (February to June 2020) on daily cumulative deaths by age and sex due to COVID-19 in 10 European regions, we found that the risk of death increased with age, and that men had higher mortality from COVID-19 than women in almost all age groups across Europe. In most regions, sex differences increased from ages $<60$ years to $60-69$ years but decreased thereafter with the smallest sex difference at ages $80+$ years.

Generally, women live longer than men in almost all countries of the world [2]. A recent study investigating the survival in seven populations under extreme conditions from famines, epidemics and slavery found that even when mortality is very high, women survived on average longer than men [3]. Although the biggest contribution to these differentials came from the large mortality differences among infants, the authors found that for all populations, the extreme age, defined as the age to which $5 \%$ of the population survived, was higher for women than for men, supporting the hypothesis of an overall ability of females to withstand higher mortality crises better than males [3]. The study supports that the survival advantage of women has fundamental biological underpinnings and also that the female advantage is modulated by a complex interaction of biological, environmental and social factors [3].

The higher mortality from COVID-19 for men than for women was overall similar to that found for other coronaviruses during the last two decades, such as the severe respiratory syndrome coronavirus (SARS-CoV) and the Middle East respiratory syndrome (MERS$\mathrm{CoV}$ ) [14-17]. The reasons for the sex differences in COVID-19 are likely multifactorial and include differences in immune response, biological differences between the sexes as well as differences in underlying comorbidities [18-20]. Although recent evidence suggests that European women overall have slightly more comorbidities than European men [21], men are generally reported to have more life-threatening conditions, such as cardiovascular diseases, whereas women tend to have more non-fatal chronic diseases, such as migraine, musculoskeletal and autoimmune diseases as well as physical limitations [22-25]. Thus, the higher risk of death from COVID-19 among men may to some extent be explained by the relatively higher prevalence of underlying comorbidities such as cardiovascular disease, hypertension, diabetes and chronic lung disease [10, 26, 27]. Nevertheless, sex differences in health depend on the selected health dimension and the age group studied, and not all outcomes show differences between sexes or show very little differences $[28,29]$. Moreover, men and women occupy different social roles, which makes valid comparisons in health outcomes difficult. When comparing men and women of similar social and economic situations, differences between sexes are generally reduced [28, 30]. Another possible reason for the sex differences in COVID-19 mortality is differences in lifestyle, such as smoking and alcohol consumption between men and women [31]. A systematic review including evidence from five studies found that smokers were 1.4 times more likely than non-smokers to have severe symptoms of COVID-19 and were around 2.4 times more likely to need mechanical ventilation, to be admitted to an intensive care unit or to die compared with non-smokers [32]. Thus, the higher risk-taking behavior in men than in women, including a higher prevalence of male smokers, may also contribute to sex differences in COVID-19 mortality $[31,33,34]$.

Although we demonstrated a higher mortality from COVID-19 for men than for women in almost all age groups, we found, as hypothesized, a reduction in the relative risk of mortality for men at later ages, consistent with findings elsewhere [12]. A narrowing of the sex gap with increasing age may be consistent with a survival effect, which leaves the healthiest men in the sample [1]; however, if estrogen protects women from the most serious complications of COVID-19, women may be most protected before the menopause due to the higher serum estrogen levels [35]. 
Evidence from studies investigating sex differences in COVID-19 mortality stresses the importance of addressing the impact of sex differences on disease epidemics, outbreaks, and pandemics in public health policies and efforts. All regions should report data separately by sex, and research studies should, whenever possible, analyze the interactions between age and sex in COVID-19 morbidity and mortality [11].

The strength of this study was the ability to analyze sex differences in COVID-19 mortality by age groups in 10 European regions showing an overall similar pattern of sex differences, despite the variability in data collection and time coverage among regions. Not all countries have reported data separately by sex, and this study was limited to the European regions providing sex-disaggregated data. Another limitation was that the frequency, recording and reporting of COVID19 deaths differ from one region to another, but may also differ within regions. The cause of death can be certified by different biological tests, by clinical diagnosis, and by mentioning the infection on the death certificates [13]. Therefore, a cross-national comparison of results should be done with caution.

By using population data on daily cumulative deaths due to COVID-19 from 10 European regions, we confirmed a consistently higher mortality from COVID-19 among European men than among European women in almost all age groups. In most regions, sex differences increased from ages $<60$ years to 60-69 years but decreased thereafter, with the smallest sex difference at ages $80+$ years in all regions. This study highlights the importance of addressing the impact of sex on mortality from disease epidemics, but studies using individual-level data are needed to confirm an interaction between age and sex in COVID-19 mortality in order to guide clinical care personnel and to address questions of whether men require additional surveillance, prevention, and earlier intervention than women.

Funding This study was supported by research Grants from Demography of Sex Differences in Health and Survival P01 AG031719.

Author Contribution All authors contributed to the study conception and design. Material preparation, data collection and analyses were performed by Martina Otavova. Linda Juel Ahrenfeldt assisted data analyses and drafted all versions of the manuscript. All authors revised the paper critically and approved the final manuscript.

Conflict of interest L.J. Ahrenfeldt, M. Otavova, K. Christensen, and R. Lindahl-Jacobsen declare that they have no competing interests.

\section{References}

1. Austad SN, Fischer KE. Sex differences in lifespan. Cell Metab. 2016;23(6):1022-33.

2. Barford A, Dorling D, Davey SG, Shaw M. Life expectancy: women now on top everywhere. BMJ. 2006;332(7545):808.
3. Zarulli V, Barthold Jones JA, Oksuzyan A, Lindahl-Jacobsen R, Christensen K, Vaupel JW. Women live longer than men even during severe famines and epidemics. Proc Natl Acad SciU SA. 2018;115(4):E832-E40.

4. Guan WJ, Ni ZY, HuY, Liang WH, Ou CQ, He JX, et al. Clinical characteristics of coronavirus disease 2019 in China. NEngl JMed. 2020;382(18):1708-20.

5. JOHNS HOPKINS University \& Medicine. Coronavirus resource center. 2020. https://coronavirus.jhu.edu/map. html. Accessed 27 June 2020.

6. Xie J, Tong Z, Guan X, Du B, Qiu H. Clinical characteristics of patients who died of coronavirus disease 2019 in China. JAMANetw Open. 2020;3(4):e205619.

7. Jin JM, Bai P, He W, Wu F, Liu XF, Han DM, et al. Gender differences in patients with COVID-19: focus on severity and mortality. Front Public Health. 2020;8:152.

8. Dudley JP, Lee NT. Disparities in age-specific morbidity and mortality from SARS-coV-2 in China and the republic of Korea. Clin Infect Dis. 2020;71(15):863-5. https://doi.org/ $10.1093 / \mathrm{cid} / \mathrm{ciaa354}$.

9. Qian J, Zhao L, Ye RZ, Li XJ, Liu YL. Age-dependent gender differences of COVID-19 in mainland China: comparative study. Clin Infect Dis. 2020;71(9):2488-94. https://doi.org/ $10.1093 / \mathrm{cid} / \mathrm{ciaa} 683$.

10. Global Health 50/50. Sex, gender and COVID-19: overview and resources. 2020. https://globalhealth5050.org/ covid19. Accessed 27 June 2020.

11. Gebhard C, Regitz-Zagrosek V, Neuhauser HK, Morgan R, Klein SL. Impact of sex and gender on COVID-19 outcomes in Europe. Biol SexDiffer. 2020;11(1):29.

12. Promislow DEL. A geroscience perspective on COVID-19 mortality. J Gerontol A Biol Sci Med Sci. 2020;75(9):e30-3. https://doi.org/10.1093/gerona/glaa094

13. Institut National D'Etudes Demographiques (INED) COVID-19. Demographics of COVID-19 deaths. 2020. https://dc-covid.site.ined.fr/en/data/. Accessed 30 June 2020.

14. Matsuyama R, Nishiura H, Kutsuna S, Hayakawa K, Ohmagari N. Clinical determinants of the severity of Middle East Respiratory Syndrome (MERS): a systematic review and meta-analysis. BMCPublic Health. 2016;16(1):1203.

15. Karlberg J, Chong DS, Lai WY. Do men have a higher case fatality rate of severe acute respiratory syndrome than women do? Am J Epidemiol. 2004;159(3):229-31.

16. Leong HN, Earnest A, Lim HH, Chin CF, Tan C, Puhaindran ME, et al. SARS in Singapore-Predictors of disease severity. Ann Acad Med Singapore. 2006;35(5):326-31.

17. Alghamdi IG, Hussain II, Almalki SS, Alghamdi MS, Alghamdi MM, El-Sheemy MA. The pattern of Middle East respiratory syndrome coronavirus in Saudi Arabia: a descriptive epidemiological analysis of data from the Saudi Ministry of Health. IntJGen Med. 2014;7:417-23.

18. Bartz D, Chitnis T, Kaiser UB, Rich-Edwards JW, Rexrode KM, Pennell PB, et al. Clinical advances in sex- and genderinformed medicine to improve the health of all: a review. JAMA Intern Med. 2020;180(4):574-83. https://doi.org/10. $1001 /$ jamainternmed.2019.7194.

19. Klein SL, Flanagan KL. Sex differences in immune responses. Nat RevImmunol. 2016;16(10):626-38.

20. Sharma G, Volgman AS, Michos ED. Sex differences in mortality from COVID-19 pandemic: are men vulnerable and women protected? JaCC Case Rep. 2020;2(9):1407-10. https://doi.org/10.1016/j.jaccas.2020.04.027.

21. Ahrenfeldt LJ, Moller S, Thinggaard M, Christensen K, Lindahl-Jacobsen R. Sex differences in comorbidity and frailty in Europe. Int J Public Health. 2019;64(7):1025-36. 


\section{short report}

22. Scheel-Hincke LL, Möller S, Lindahl-Jacobsen R, Jeune B, AhrenfeldtLJ.Cross-national comparison of sex differences in ADL and IADL in Europe: findings from SHARE. Eur J Ageing. 2020;17(1):69-79.

23. Case A, Paxson C. Sexdifferences in morbidity and mortality. Demography. 2005;42(2):189-214.

24. Whitacre CC. Sex differences in autoimmune disease. Nat Immunol. 2001;2(9):777-80.

25. Crimmins EM, Kim JK, Sole-Auro A. Gender differences in health: results from SHARE, ELSA and HRS. Eur J Public Health. 2011;21(1):81-91.

26. Salah HM, Mehta JL. Hypothesis: sex-related differences in ACE2 activity may contribute to higher mortality in men versus women with COVID-19. J Cardiovasc Pharmacol Ther. 2020;https://doi.org/10.1177/1074248420967792.

27. Ahrenfeldt LJ, Nielsen CR, Möller S, Christensen K, LindahlJacobsen R. Burden and prevalence of risk factors for severe COVID-19 disease in the ageing European population-A SHARE-based analysis. Res Sq. 2020;https://doi.org/10. 21203/rs.3.rs-73657/v1.

28. Walters V, McDonough P, Strohschein L. The influence of work, household structure, and social, personal and material resources on gender differences in health: an analysis of the 1994 Canadian National Population Health Survey. Soc Sci Med. 2002;54(5):677-92.

29. Ahrenfeldt LJ, Scheel-Hincke LL, Kjaergaard S, Moller S, Christensen K, Lindahl-Jacobsen R. Gender differences in cognitive function and grip strength: a cross-national comparison of four European regions. Eur J Public Health. 2019;29(4):667-74.

30. EmslieC,HuntK, MacintyreS. Problematizing gender, work and health: the relationship between gender, occupational grade, working conditions and minor morbidity in full-time bankemployees. Soc Sci Med. 1999;48(1):33-48.

31. Abate BB, Kassie AM, Kassaw MW, Aragie TG, Masresha SA. Sex difference in coronavirus disease (COVID19): a systematic review and meta-analysis. BMJ Open. 2020;10(10):e40129.

32. Vardavas CI, Nikitara K. COVID-19 and smoking: a systematic review of the evidence. Tob Induc Dis. 2020;18:20.

33. Riahi M, Mohammadi AA, Rohani H, Bidkhori M. Dataset on the prevalence of tobacco smoking in men and women of selected countries whit difference human development. Data Brief. 2018;18:506-11.

34. Oksuzyan A, Juel K, Vaupel JW, Christensen K. Men: good health and high mortality. Sex differences in health and aging. Aging Clin Exp Res. 2008;20(2):91-102.

35. Grandi G, Facchinetti F, Bitzer J. The gendered impact of coronavirus disease (COVID-19): do estrogens play a role? Eur J Contracept Reprod Health Care. 2020;25(3):233-4. https://doi.org/10.1080/13625187.2020.1766017.

Publisher's Note Springer Nature remains neutral with regard to jurisdictional claims in published maps and institutional affiliations. 